\title{
A novel device to measure tactile reaction time
}

\author{
Rajpoot RS*1, Tandon $S^{2}$, Kumar $P^{3}$, Mittal $K^{4}$, Awasthi $S^{5}$, Kumar $A^{6}$ \\ ${ }^{1}$ Dr. Raveendra Singh Rajpoot, Associate Professor, Department of Physiology, UPRIMS\&R, Etawah, ${ }^{2}$ Dr Stuti Tandon, \\ Junior Resident, Department of Anatomy, KGMU, Lucknow, ${ }^{3}$ Dr. Pradeep kumar, Professor, Department of Physiology, \\ KGMU, Lucknow, ${ }^{4}$ Kailash Mittal, Assistant Professor, Department of Radiotherapy, UPRIMS\&R, Etawah, ${ }^{5}$ Dr. \\ Sankalp Awasthi, Assistant Professor, Department of Dermatology, UPRIMS\&R, Etawah, ${ }^{6}$ Dr. Ajai Gupta, \\ Demonstrator, Department of Biochemistry, UPRIMS\&R, Etawah.
}

Address for Correspondence: Dr. Raveendra Singh Rajpoot, Associate Professor, Department of Physiology, UPRIMS\&R, Etawah. Email: drrsrajpoot@yahoo.com

\begin{abstract}
Introduction: Reaction Time has been widely used as one of the measures of mental chronometry since very long. Most of the work has been done with visual and auditory reaction time. Till now reaction time has never been measured by giving tactile stimuli. Hence we have designed a new device to provide different tactile stimuli and to simultaneously measure the time taken by the subject to respond to it. Probably for the first time in the history of mental chronometry Tactile Choice Reaction Time has been compared between males and females. Methods and Materials: The study was conducted among 53 male and 34 female healthy subjects who were between the age group of 18- 24 years. A new instrument has been designed by the author of this article to deliver tactile stimuli on the skin of the subject and to measure the reaction time for that particular sensory modality. Result: All the reaction times were found to be significantly faster in males than in females except for fine touch. For fine touch although the RT is faster in males but the difference is not statistically significant. Conclusion: Present study has reconfirmed the gender differences in case of tactile choice reaction time also. It is going to be really interesting with the use of this new device to find out the relationship of various Tactile Choice Reaction Times with these conditions.
\end{abstract}

Key words: Reaction Time, Tactile, Mental Chronometry

\section{Introduction}

Reaction Time is the interval between presentation of the stimulus and the subsequent behavioral response. The behavioral response is typically a button press but it can be vocal response or any other recognizable response of the subject. In general terms it involves both the central and the peripheral parts of the nervous system. Firstly the central nervous system has to recognize the stimulus relayed to it via peripheral nervous system and then decided response again travels via peripheral nerves to the effector organ, for example the fingers. The fingers then press a button to give a response. It can be considered as an indirect method of measuring processing ability of our brain [1].

The response time is the sum of reaction time plus the

Manuscript received: $30^{\text {th }}$ Oct 2015

Reviewed: $9^{\text {th }}$ Nov 2015

Author Corrected: $20^{\text {th }}$ Nov 2015

Accepted for Publication: $4^{\text {th }}$ Dec 2015 time taken by the subject's movement to show the response. Hence to measure the reaction time the experiment should be designed in such a way so as to minimize the movement time as much as possible.

Types of reaction time [2-4]:

1. Simple reaction time is the movement of the subject to the presence or absence of the stimulus. For example the subject may be asked to show a response to presence of a visual or auditory stimulus. Mean reaction times of young individuals is about 160 milli seconds for auditory and 190 milli seconds for visual stimuli $[2,3]$.

2. Recognition reaction time is the response to the particular type of stimulus not to just presence or absence of it. For example presence of a particular type 
of sound or particular color of light is responded to.

3. Choice reaction time is comprised of differential response to a different stimulus. For example different button is pressed for different color of light.

Clinical / Applied importance of Reaction Time measurement: There has been extensive research using reaction time and other measures of mental chronometry for the study of cognitive development. It has been shown to improve gradually with age as the child grows up, attains a plateau and then starts declining with senescence [4]. The speed of processing has been shown to be closely associated with working memory and thought [5].

There is a tendency for individuals with higher IQ to have faster reaction times. The strength of Reaction Time - IQ association has been shown to be $(r=-31)$ for simple reaction time and $(\mathrm{r}=-49)$ for choice reaction time [6].

With the emergence of newer neuroimaging techniques like PET and fMRI Reaction Time is being used in imaging those parts of brain which are concerned with cognitive processes [7].

Recent research work indicate that probably signaling through dopamine pathway in tegmental area of the brain is involved in processing of the messages in reaction time. This has given us a tool in the form of dopaminergic pharmaceuticals to affect the individuals reaction time.

On comparing simple auditory and visual reaction time it was found that ART (auditory reaction time) are faster than VRT (visual reaction time) [8,9]. This difference is most probably due to the faster conduction of auditory stimulus to the cortex taking almost $8-10 \mathrm{~ms}$ in comparison to visual stimuli which takes $10-20 \mathrm{~ms}$.

Till now reaction time has never been measured by giving a tactile stimuli. Hence we have designed a new device to provide different tactile stimuli and to simultaneously measure the time taken by the subject to respond to it.

\section{Materials and Methods}

The study was conducted among 53 male and 34 female healthy subjects who were between the age group of 1824 years. Nature of the study was explained and informed consent was obtained from each of the subjects before their participation in the study. The protocol of the study was approved by the institutional ethical committee. A thorough history was collected and clinical examination was performed to rule out any neurological, psychiatric or any other diseases for all the subjects before intervention. Clinical characteristics are summarized in the table1.

Table 1: Clinical Characteristics of the Subjects:

\begin{tabular}{|l|l|l|}
\hline \multirow{2}{*}{ No of Subjects } & Variables \\
\cline { 2 - 3 } & Age & Body weight \\
\hline Males (53) & $20.32 \pm 2.41$ & $54 \pm 3.78$ \\
\hline Females (34) & $19.89 \pm 2.22$ & $52 \pm 4.27$ \\
\hline
\end{tabular}

Devices: A new instrument has been designed by the author of this article to deliver a tactile stimuli on the skin of the subject and to measure the reaction time for that particular sensory modality. The whole instrument is comprised of following parts (Fig 1):

1. Stimuli applicator device.

2. Digital stop watch.

3. A release button.

4. Connections . 


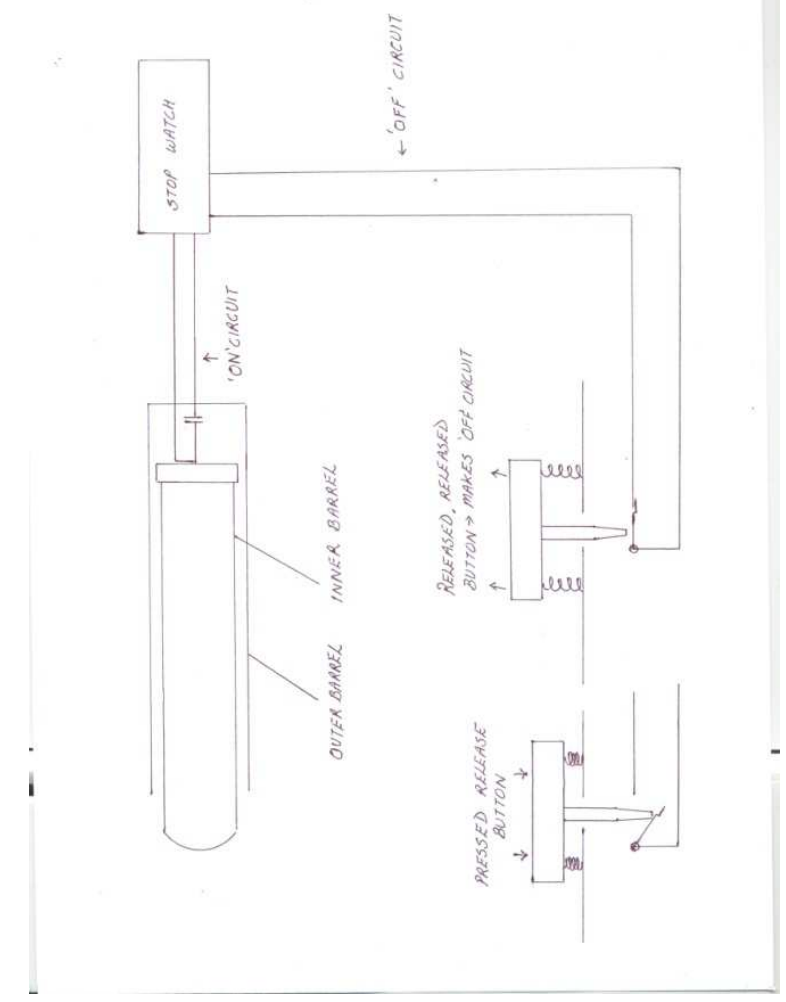

Stimuli applicator device: This device grossly looks like a big marker pen with a electric cable attached to its rear end. It is comprised of an outer and an inner barrel. The outer barrel is made of plastic and the inner barrel is a small test tube with a cap. The inner barrel has various modifications to apply fine touch, crude touch, hot, cold or vibration stimuli. The outer barrel remains same for all these modifications.

The Connection between outer and inner barrel: once inserted into the outer barrel, a spring system continuously pushes the inner barrel downwards, but the inner barrel is prevented from coming out by a latch system. When the tip of the test tube (the inner barrel) is touched to the skin of the subject, it gets pushed inside this completes the 'on' circuit of the stop watch and the time starts running in it.

\section{Modifications of Inner Barrel:}

For Fine Touch: a conical aluminum attachment in glued to the tip of the inner barrel tip (test tube tip).

For Crude Touch: unmodified base of inner tube (test tube) serves to provide crude touch.

For Vibration: A battery operated mobile phone vibrator is attached to the inner cavity of the inner tube (test tube). It's on off switch is provided of the console. When put on it vibrates the inner barrel at a frequency between 130 - 200 hertz. This vibrating tip of inner barrel is used to provide sense of vibration on the bony prominences of the subject.

For Hot Sensation: the inner barrel is filled with warm water, its cap is closed and it is placed into the outer barrel. Its tip is now used to deliver warm stimuli to the subject.

For Cold Sensation: the inner barrel (test tube) is filled with cold water capped, placed into outer barrel and used to apply cold sensation.

Digital Stop Watch: it is fitted on a console and has got two circuits. One is 'on' circuit which gets completed as soon as the tip of the stimuli applicator is touched to the skin of the subject. Other circuit is 'off' circuit which gets completed as soon as the subject releases pressure from the release button. This stops the time in the stop watch which can be recorded as the reaction time of the subject for that stimuli. 
Release Button: is a specially designed button to minimize the movement time. It is kept pressed by the subject when he is ready to receive the stimulus. As the stimulus is applied on the subjects body, the subject recognizes it and if he decides to respond to it, he releases pressure from the button. This makes the 'off' circuit of the stop watch and the time stops running in it. This enables us to minimize the wastage of time in making the movement to show a response. In many of the conventional machines the person has to reach up to a button and press it so as to register his response. In our instrument these two stages are cut off, this helps in getting a prompt reaction time response.

Connections: the only cable visible outside is the one connecting stimulus applicator to the console which harbors the stop watch and the release button.

Mechanism of operation of the instrument: when the tip of the inner barrel is used to deliver stimulus to the subject, it moves up into the outer barrel. This movement completes the 'on' circuit of the stop watch and it starts running. As the subject feels the sensation he or she releases the release button which was kept pressed by him earlier. This release of the release button makes the 'off' circuit of the stop watch and the time in the watch stops. This is the duration of reaction time of that subject for that modality.

The Zero Error of The Device: As it can be appreciated from the design of the stimulus applicator device a very slight gap is present between the electric points of inner and outer barrels. This gap can be adjusted with the help of a screw system. When the tactile stimulus is delivered by the device, the inner barrel moves in and both the electrical points come close to each other thus making the 'on' circuit of the stop watch. Depending upon the distance between the two electrical points some time is taken by these two points to touch each other. This time can be calculated by making a small modification in the device itself. Once calculated it should be subtracted from the final reading of the stopwatch. This should be regarded as the zero error of the device.

\section{Results}

Tactile reaction times were measured and compared for the first time in healthy males and females of age group 18 - 24 years. All the reaction times were found to be significantly faster in males than in females except for fine touch. For fine touch although the RT is faster in males but the difference is not statistically significant, as shown in Table 2.

Table 2: Gender differences in different Tactile Choice Reaction Time Values:

\begin{tabular}{|l|l|l|l|}
\hline $\begin{array}{l}\text { Reaction Time for different tactile } \\
\text { Sensory modalities }\end{array}$ & Male RT(ms) & Female RT(ms) & P value \\
\hline Touch & $271 \pm 12.53$ & $306.33 \pm 23.63$ & 0.08 \\
\hline Pressure & $283 \pm 13$ & $313 \pm 12.34$ & 0.042 \\
\hline Vibration & $289.67 \pm 19.43$ & $337 \pm 19.08$ & 0.039 \\
\hline Cold & $211 \pm 19$ & $259.33 \pm 22$ & 0.0451 \\
\hline Hot & $137.67 \pm 35.84$ & $216.33 \pm 33.32$ & 0.0496 \\
\hline
\end{tabular}

\section{Discussion}

The Tactile Reaction Time has probably been done for the first time in the long history of experimentation with different methods of mental chronometry. The findings of our study have reconfirmed the fact that males have faster reaction times than females [10-14]. The difference between males and females have been found due mostly to the time required for the processing of the stimulus, as the response time by the musculoskeletal system is almost similar in both of them [15], although the male responses are more powerful [16]. One more possibility lies in the difference in the physical activity between males and females. It is a well documented fact that individuals engaged in physical activity like different sports tend to have shorter reaction times [4,17-23].The results of the preliminary run of the device have been done of very small group of subjects hence it would be rather too optimistic to draw final conclusion from this study. Although the results are in conformity with so many studies done in the past which 
have shown the influence of gender on RT in almost every age group.

\section{Conclusion}

Till now probably hundreds of studies have been done with visual and auditory reaction time machines. Hundreds of factors and conditions have been found to affect Reaction Times including gender and age differences. Recently its has been found to get affected in so many neurological diseases like Alzheimer and other degenerative and age related diseases. Present study has reconfirmed the gender differences in case of tactile choice reaction time also. It is going to be really interesting with the use of this new machine to find out the relationship of various Tactile Choice Reaction Times with these conditions.

\section{Funding:Nil. Conflict of interest: Nil. Permission for IRB: Yes}

\section{References}

1. Lofthus GK. The sensory motor performance and the limb preference. Percepts Mot or Skills. 1981 Jun;52(3):688-93.

2. Duke-Elder S. Franciscus Cornelis Donders. Br J Ophthalmol. 1959 Feb;43(2):65-8.

3. Luce RD. London: Academic Press; 1968. [Last accessed on 2011 Aug 08]. Information Theory of Choice. Reaction Times. Available from: http://www.biology.clemson.edu/bpc/bp/Lab/11 0/reaction.htm.

4. Welford AT. Choice reaction time: Basic concepts. In: Welford AT, editor. Reaction Times. New York: Academic Press; 1980. pp. 73-128.

5. Kosinski RJ. A literature review on reaction time, Clemson University (2008).

6. Taoka, George T. Mrake Reaction Times of Unalerted Drivers. ITE Journal 1989 Mar;59(3):1921.

7. Salthouse TA. Aging and measures of processing speed. Biological Psychology 2000 Oct;54(1-3):3554.

8. Pain MT, Hibbs A. Sprint starts and the minimum auditory reaction time. J Sports Sci. 2007 Jan;25(1):79-86.

9. Thompson PD, Colebatch JG, Brown P, Rothwell
JC, Day BL, Obeso JA, et al. Voluntary stimulussensitive jerks and jumps mimicking myoclonus or pathological startle syndromes. Mov Disord. 1992;7(3):257-62.

10. Noble D, Baker BL, Jones TA. Age and sex parameters in psychomotor learning. Percept Mot Skills 1964 Dec;19:935-45.

11. Adam JJ, Pass FG, Buekers MJ, Wuyts IJ, Spijkers WA, Wallmeyer P. Gender differences in choice reaction time: Evidence for differential strategies. Ergonomics 1999 Feb;42(2):327-35.

12. Der G, Deary IJ. Age and sex differences in reaction time in adulthood. Results from the United Kingdom Health and Lifestyle Survey. Psychol Aging 2006 Mar;21(1):62-73.

13. Misra N, Mahajan KK, Maini BK. Comparative study of visual and auditory reaction time of hands and feet in males and females. Indian $\mathbf{J}$ Physiol Pharmacol 1985 Oct-Dec:29(4):213-8.

14. Nikam LH, Gadkari JV. Effect of age, gender and body mass index on visual and auditory reaction time in Indian population. Indian $\mathbf{J}$ Physiol Pharmacol 2012 Jan-Mar;56(1):94-9.

15. Botwinick J, Thompson LW. Components of reaction time in relation to age and sex. $\mathrm{J}$ Genet Psychol.1966 Jun;108(second half):175-83.

16. Nakamoto H, Mori S. Sport-specific decisionmaking in a Go/NoGo reaction task: Difference among nonathletes and baseball and basketball players. Percept Mot Skills. 2008 Feb;106(1):163-70.

17. Ghuntla TP, Mehta HB, Gokhale PA, Shah CJ. A comparative study of visual reaction time in basketball players and healthy controls. Natl $\mathbf{J}$ Integr Res Med. 2012;3:49.

18. Spirduso WW. Reaction and movement time as a function of age and physical activity level. J Gerontol.1975 Jul;30(4):435-40.

19. Gavkare AM, Nanaware NL, Surdi AD. Auditory reaction time, visual reaction time and whole body reaction time in athletes. Ind Med Gaz. 2013;6:214-9.

20. Welford AT. London: Menthuen; 1968. [Last accessed on 2011 Aug 08]. Fundamentals of Skill. Available

from: http://www.biology.clemson.edu/bpc/bp/Lab/11 0/reaction.htm. 
21. Demetriou A, Mouyi A, Spanoudis G. Modeling the structure and deveopment of $\mathrm{g}$. Intelligence 2008;5(5):437-54.

22. Deary IJ, Der G, Ford G. Reaction times and intelligence differences. A population based cohort study. Intelligence 2001;29(5):389-99.

23. Posner, Michael K. Timing the Brain: Mental Chronometry as Tool in Neuroscience. PLoS Biology 2005 Feb;3(2):e51.

\section{How to cite this article?}

Rajpoot RS, Tandon S, Kumar P, Mittal K, Awasthi S, Kumar A. A novel device to measure tactile reaction time . Int J Med Res Rev 2015;3(11):1294-1299. doi: 10.17511/ijmrr.2015.111.235. 